\title{
Genetic variation and gene flow in Alpine diploid and tetraploid populations of Lotus (L. alpinus (D.C.) Schleicher/L. corniculatus L.). I. Insights from morphological and allozyme markers
}

\author{
PERRINE GAUTHIER*†‡, ROSELYNE LUMARET† \& ALAIN BÉDÉCARRATS‡ \\ tCentre Louis Emberger - CEFE/CNRS, 1919 route de Mende, F-34293 Montpellier Cedex 5, France, and \\ ‡CEMAGREF - Groupement de Grenoble, BP 76, F-38402 Saint Martin d'Héres Cedex, France
}

\begin{abstract}
The altitudinal distribution, morphology, phenology and allozyme polymorphism at 12 loci were studied in diploid and tetraploid populations of Lotus growing at over $1800 \mathrm{~m}$ in the French Alps to clarify relationships between these cytotypes. In general, diploids occurred at higher elevation than tetraploids, although some sites at intermediate elevation contained both cytotypes, diploids predominating in the upper part and tetraploids in the lower part of the contact area. Evidence for an autopolyploid origin of the tetraploids was provided by tetrasomic inheritance at two enzyme loci, although no tetravalents were observed at meiosis. Diploid and tetraploid plants shared morphological traits distinct from those of other Lotus species and showed differences in size, which may be attributable to chromosome doubling. The diploid cytotype, L. alpinus, may thus be the ancestor of the Alpine tetraploids. Both cytotypes showed nearly identical suites of alleles at all loci and very similar genetic parameters, except for heterozygosity, which was higher in the tetraploid plants. However, the occurrence of few alleles specific to each ploidy level indicated limited gene flow between cytotypes, probably as a result of spatial segregation and variation in flowering time. Of the individuals in a tetraploid population, $25 \%$ showed morphological traits similar to those observed in L. corniculatus, suggesting genetic introgression between the two tetraploid species.
\end{abstract}

Keywords: allozyme variation, genetic introgression, Lotus alpinus/corniculatus, morphological differentiation, polyploid complex.

\section{Introduction}

The evolutionary dynamics of polyploid complexes depend on two contrasting evolutionary trends. First, spatial or niche differentiation and partial reproductive isolation may occur between the different taxonomic entities of the complex. Such differentiation between taxa may facilitate their co-existence over time even in sympatric situations and may lead to the occurrence of substantial genetic differentiation between them (Thompson \& Lumaret, 1992). A secondary evolutionary trend influencing polyploid evolution is that some genetic cohesion may be maintained within the polyploid

*Correspondence. E-mail: pgauthie@cefe.cnrs-mop.fr complex as a result of occasional gene flow between the entities. Such gene flow may occur because of multiple polyploidization events in space and/or time or by direct crosses between individuals belonging to distinct entities, particularly in secondary contact areas (Bretagnolle \& Thompson, 1995). Therefore, the phylogenetic relationships among the taxa of a given polyploid complex are difficult to identify precisely and have been elucidated only in a restricted number of studies using isozyme electrophoresis and DNA markers (see Soltis \& Soltis, 1993 for a review).

The polyploid complex Lotus in Europe contains several diploid $(2 n=2 \mathrm{x}=12)$ and tetraploid $(2 n=4 x=24)$ taxa whose phyletic relationships remain poorly understood. In the Alps, the occur- 
rence of several perennial species of Lotus (Fabaceae) has been reported. The diploid plants have been identified either as L. tenuis L., which occurs at low altitude (Small et al., 1984), or as L. alpinus (D.C.) Schleicher, occurring at high elevation (from about 2000-3000 m). Several controversial theories have been proposed concerning the identity and origin of tetraploid Lotus species usually found from $1800 \mathrm{~m}$ to $2500 \mathrm{~m}$. First, Favarger (1969) described the two cytotypes as distinct species, considering the diploid $L$. alpinus as specific to high altitudes and the tetraploid $L$. corniculatus as specific to lower altitudes. Secondly, after studying the $L$. corniculatus complex along an altitudinal gradient in Turkey, Small et al. (1984) showed that, although L. corniculatus and L. alpinus exhibit morphological, chromosomal and ecological differences, these are not sufficient for them to be identified as separate species. In the Swiss Alps, based on the chromosomal resemblance of both cytotypes, UrbanskaWorytkiewicz \& Wildi (1975) and UrbanskaWorytkiewicz et al. (1979) considered the polyploid as a tetraploid cytotype of L. alpinus. However, despite an extensive survey of Swiss populations, Urbanska-Worytkiewicz \& Wildi (1975) found no triploid individuals and observed only rare mixed populations occurring in disturbed areas. Moreover, from a study of intra- and intercytotype reproductive behaviour, Urbanska-Worytkiewicz et al. (1979) showed a strong reproductive barrier between the two cytotypes and concluded that gene flow between the diploid and the tetraploid cytotypes is limited.

More recently, in their survey on the differentiation of $L$. corniculatus/L. alpinus populations from the French Alps, Blaise et al. (1991) and Jay et al. (1991) refer to diploid $L$. alpinus and tetraploid $L$. corniculatus. Unlike the previous authors, they found a substantial number of mixed populations but, again, no triploid individuals. Although Blaise et al. (1991) and Jay et al. (1991) easily discriminated between the cytotypes based on morphological characters and polyphenolic patterns, they also described tetraploids with diploid-like or intermediate morphology and/or chemotype. Thus, they suggested that the tetraploid cytotype may have had an autotetraploid origin from $L$. alpinus through the formation of unreduced gametes. Several studies, reviewed by Grant \& Small (1996), have been conducted on genetic variation in the $L$. corniculatus group using markers, such as isozymes (Realson \& Grant, 1988, 1989) or RAPDs (Campos et al., 1994). Unfortunately, Alpine tetraploid Lotus material was not involved in these studies.
The objective of the present work was to clarify the identity and origin of tetraploid Lotus in the Alps. This paper is the first of two and deals with morphological and allozyme variation in diploid and tetraploid Lotus populations growing along altitudinal gradients in the French Alps (Savoy region). Additional tetraploid material clearly identified as $L$. corniculatus from other regions was also analysed for comparative purposes. In a second paper, using the same plant material, we present the results based on a survey of chloroplast DNA variation, a cytoplasmic marker that is transmitted maternally in Lotus (Gauthier et al., 1997). In the present paper, we have three objectives: (i) to describe the altitudinal and habitat distribution of both cytotypes; (ii) to discriminate between possible auto- or allopolyploid origins of the Alpine tetraploids based on observations of chromosome behaviour at meiosis and by observing isozyme inheritance patterns; and (iii) to study genetic variation within and between the tetraploid and diploid populations and thence to quantify any gene flow between them.

\section{Materials and methods}

Plant material

Individual Lotus plants were sampled along two altitudinal transects on schistose substrate, located $22 \mathrm{~km}$ apart in the Tarentaise valley of the French Alps at 'La Sassière' and 'Mount Jovet'. The altitudinal range (1800-2600 m) corresponded to a transitional area from upper subalpine meadows on fallen rock slopes covered with shallow soils ( $\mathrm{pH} 7)$ to Alpine grassland ( $\mathrm{pH}$ 6) subject to snow accumulation. The climatic characteristics are summarized in Table 1. Carex sempervirens and Elyna myosuroides were the most representative plant species of the subalpine and Alpine habitats respectively.

Throughout the altitudinal gradient, a cytological survey was made, and in situ flowering phenology was studied by direct observation of Lotus plants during the summers of 1995 and 1996. In addition, for both transects, Lotus plants were sampled in the populations located at the highest elevation (2500-2600 m, populations 1 and 2) and at the lowest elevation (1800 $\mathrm{m}$, populations 3 and 4) to study both morphological and allozyme variation (Table 1). Allozyme analysis was also performed using an additional population also from the French Alps (Val d'Isère, 5) and L. corniculatus individuals from the cultivar 'San Gabriel' (6), produced in Italy and known to have been introduced into the Alpine valleys. In each population, seeds were collected

(c) The Genetical Society of Great Britain, Heredity, 80, 683-693. 
Table 1 Location, elevation and climate characteristics of the Lotus populations and number of plants analysed for allozymes and/or morphological variation

\begin{tabular}{|c|c|c|c|c|c|c|c|c|}
\hline Sources & No. & $\begin{array}{l}\text { Elevation } \\
\quad(\mathrm{m})\end{array}$ & Exposure & $\begin{array}{c}\text { Mean annual } \\
\text { temperature }\left({ }^{\circ} \mathrm{C}\right) \dagger\end{array}$ & $\begin{array}{c}\text { Snow } \\
\text { cover (days) } \ddagger\end{array}$ & $2 n$ & $\begin{array}{l}\text { Morphology } \\
\text { sample size }\end{array}$ & $\begin{array}{c}\text { Allozyme } \\
\text { sample size }\end{array}$ \\
\hline \multicolumn{9}{|c|}{ Alpine populations } \\
\hline Mt Jovet & 2 & 2500 & $\mathrm{~S}$ & 0.0 & 225 & 12 & 40 & 32 \\
\hline La Sassière & 3 & 1800 & SW & 3.1 & 176 & 24 & 40 & 32 \\
\hline \multicolumn{9}{|c|}{ Lotus corniculatus cultivar } \\
\hline San Gabriel & 6 & - & - & - & & 24 & - & 34 \\
\hline
\end{tabular}

$\dagger$ Data from the meteorological office of Bourg Saint Maurice (France), for the period from 1946 to 1960, in Gensac (1978).

†Data from Gapillout (1975).

randomly from 50 plants. The seedlings were grown in the greenhouse at the CEFE-CNRS experimental garden in Montpellier for 2 months until they were analysed. One seedling individual was analysed from each mother plant.

\section{Cytological survey}

Chromosome counts were performed on root-tip squashes using the Feulgen technique to determine ploidy level in each individual and cytotype distribution along the two transects. In addition, in order to study chromosome pairing and to check for the occurrence of tetravalents, meiosis was observed in anthers collected in situ from 10 and 12 tetraploid plants growing in populations 3 and 4, respectively. The fixing and staining methods are described by Lumaret \& Hanotte (1987).

\section{Morphological variation in the French Alpine populations}

The following characters were estimated visually in populations 1-4 in July 1995: bud colour (red or yellow); flower colour (deep or light yellow); keel tip colour (brown or yellow); leaf colour (light or deep green) and pilosity (yes or no); stem colour (green, red or brown) and pilosity (0 or 1$)$; and individual plant habit (prostrate or erect). Twelve quantitative characters, namely stem length, internode length, leaf length, leaf width, calyx length, calyx teeth length, standard length, standard width, keel length, keel width, flower number per umbel and ovary length, which have been used previously to distinguish diploid L. alpinus from $L$. corniculatus and/ or tetraploid L. alpinus (Small et al., 1984;
O’Donoughue et al., 1990; Blaise et al., 1991; Grant \& Small, 1996), were measured in situ on 40 individuals from each of the four populations. In addition, 30 plants from each population were grown from seed (one seed per mother plant) in the greenhouse and scored for these morphological characters under uniform conditions.

For each character, three measures were made on each individual plant, and the analyses were based on mean plant values. Multivariate analyses of variance (MANOVA) were carried out using PROC-GLM in SAS (SAS Institute Inc., 1990) to determine the effect of cytotype and population within cytotype on overall variation in plant phenotype. Standardized canonical co-ordinates were calculated for each trait to determine the relative contribution of each trait to variation between cytotypes and between populations within cytotypes. Mean values were also compared for two characters (leaf length and standard length) between each of the two Alpine tetraploid populations and a sample of the L. corniculatus cultivar Leo (data taken from O'Donoughue et al., 1990) using Student's $t$-tests.

A morphological index, based on three characters, namely leaf length, leaf width and keel length, was estimated for each plant measured in the field or grown under uniform conditions. This index was calculated following Brochmann (1987) on log-transformed data of the three selected traits. For each trait, the morphological character index $x_{i j}^{\prime}$ was calculated as:

$x^{\prime}{ }_{i j}=\left(x_{i j}-x_{i \min }\right) /\left(x_{i \max }-x_{i \min }\right)$,

where $x_{i j}$ is the observed value of trait $i$ on genotype $j, x_{i \min }$ is the minimum value of $i$ and $x_{i \max }$ is the 
maximum value of $i$ in the observed sample. The index varies between 0 and 1. The mean character index of each genotype was calculated as the mean of the indices for the three variables to compare the overall morphology of each genotype with all other genotypes. Because information from pure parental populations is not required (Brochmann, 1987), this method is suitable for revealing possible intermediate hybrid individuals.

\section{Allozyme analysis}

Allozyme assays were performed on leaf tissue from the 2-month-old seedlings grown in the greenhouse. A total of 190 plants (about 31 individuals per population) was scored (Table 1).

Out of the seven electrophoretic systems used previously in $L$. alpinus and $L$. corniculatus by Realson \& Grant (1988), six were tested in the present study. Four of them, namely phosphoglucose isomerase (PGI), isocitrate dehydrogenase (IDH), malate dehydrogenase (MDH) and 6-phosphogluconate dehydrogenase (6-PGDH), showed polymorphism in our experimental conditions. Four additional polymorphic systems, namely esterase (EST), acid phosphatase (AcPH), leucine aminopeptidase (LAP) and tetrazolium oxidase (TO), were also analysed.

The electrophoretic and staining techniques used in the present study were those of Realson \& Grant (1989) for IDH, MDH, 6-PGDH and PGI, of Lumaret (1988) for AcPH and TO and of Soltis \& Soltis (1989) for EST and LAP.

Inheritance of the polymorphic loci IDH1-2, MDH3, 6-PGDH1-2, 6-PGDH3-4 and PGI2-3 was studied by Realson \& Grant (1988, 1989). For AcPH, EST and LAP systems, the pattern of inheritance was assessed by analysing progeny from controlled crosses (see below). For the TO system, inheritance was inferred from data on quaternary structure and genetic control of these enzymes in other related genera (Weeden \& Wendel, 1989). In the present study, at each locus, the index value 100 was given to the most frequent allele, whereas the other ones were numbered according to their relative mobility. Correspondence between our indices and those of alleles previously identified at the same loci by Realson \& Grant (1988) is indicated in Table 4.

Allozyme segregation Allele segregation was studied at three loci, $A c P H 1$ (dimeric enzymes), EST1 and $L A P 1$ (monomeric enzymes), from progeny plants of three controlled crosses. Parent individuals were isolated in an insect-free greenhouse. Flowers of the female parent were emasculated by removing the stamens with forceps. Two days later, pollen from the male parent was applied to the stigmas of the emasculated flowers. Seeds were collected when pods became brown (between 30 and 40 days after pollination). Observed genotype frequencies were compared with expected ones on the basis of two-locus disomic or tetrasomic allelic segregations, using a $\chi^{2}$ test.

Allozyme data analysis The total number $\left(A_{\mathrm{t}}\right)$ and mean number $(A)$ of alleles per population, the percentage of polymorphic loci $(P)$, the mean observed heterozygosity $\left(H_{\mathrm{o}}\right)$ and the genetic diversity $\left(H_{\mathrm{s}}\right)$ were calculated from allele genotypes in each population. Numbers of alleles were compared using Mann-Whitney $U$-tests. In multiple comparisons, the Bonferroni correction was used. Percentage comparisons were used for $P, H_{\mathrm{o}}$ and $H_{\mathrm{s}}$ values. These data were used to calculate total genetic diversity $\left(H_{\mathrm{T}}\right)$, genetic diversity between populations $\left(D_{\mathrm{ST}}\right)$ and the proportion of diversity resulting from gene differentiation between populations $\left(G_{\mathrm{ST}}\right)$ (Nei, 1987) or between populations either within each ploidy level or between ploidies.

Nei's distances (1978) were determined between pairs of populations from their allelic distributions. These distances were used as the basis for a cluster analysis (UPGMA), total clustering scale ranging from $0 \%$ to $100 \%$, using the BIOMECO computer package (Lebreton et al., 1987).

In each diploid or tetraploid population, the genotype distribution at the studied loci (except those that were duplicated) was compared with expected values using a $\chi^{2}$ test assuming panmixia and postulating tetrasomic inheritance with the index of separation being equal to 0 in the tetraploids.

\section{Results}

Cytotype distribution and morphological variation along the two transects

For both transects, all plants in the Alpine area (populations 1 and 2) were diploid, whereas those from the subalpine meadows at the lowest elevation (populations 3 and 4) were tetraploid (Fig. 1). At La Sassière, the diploids were isolated from the tetraploids by a steep rocky area covered with scarce vegetation in which no Lotus individuals were observed. Conversely, on Mount Jovet, in the intermediate area ranging from 1900 to $2400 \mathrm{~m}$ elevation, although Lotus plants were scarce and showed a scattered distribution, a mixture of diploid and

(C) The Genetical Society of Great Britain, Heredity, 80, 683-693. 


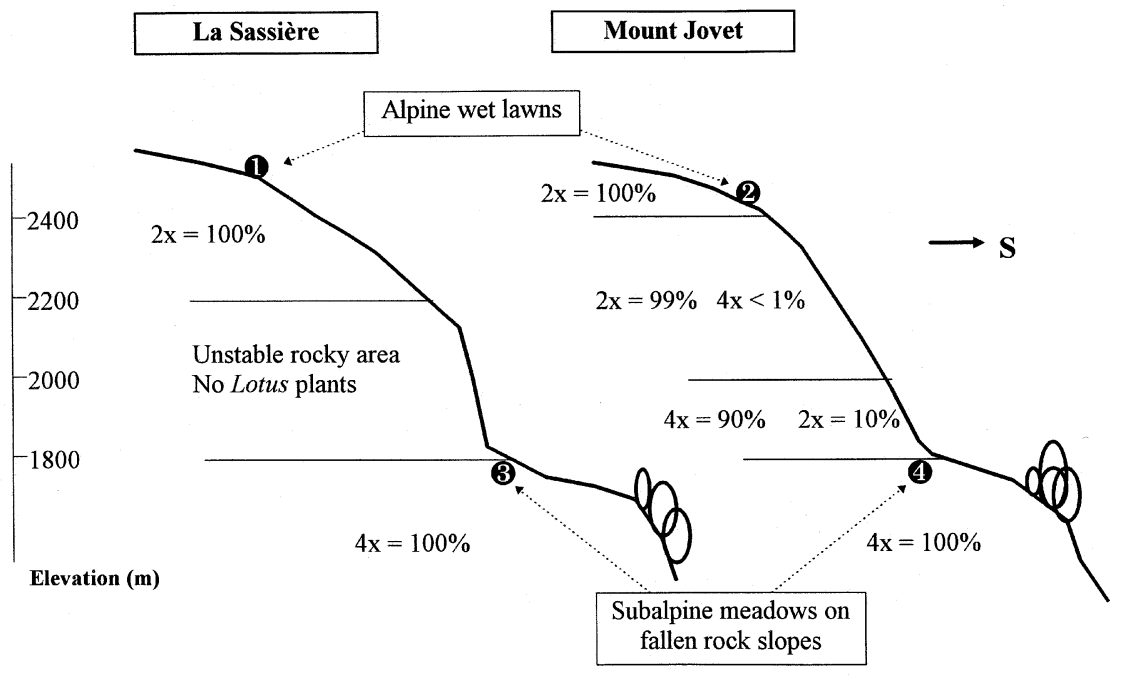

Fig. 1 Altitudinal distribution of the diploid $(2 \mathrm{x})$ and the tetraploid $(4 \mathrm{x})$ Lotus plants in two sites studied in the French Alps. tetraploid individuals was observed with a predominance of tetraploids below $2050 \mathrm{~m}$ and of diploids at higher elevations (Fig. 1).

Along both transects, the flowering period of the tetraploid plants growing below $1900 \mathrm{~m}$ lasted from around mid-June to early August, whereas that of the diploids above $2400 \mathrm{~m}$ started 1 month later (mid-July) and finished in mid-August. On Mount Jovet in the intermediate area (1900-2400 m), a longer overlapping flowering period of nearly 1 month was observed in sympatric diploids and tetraploids, although the tetraploids flowered earlier than the diploids.

The diploid and tetraploid plants from the four populations studied in situ for morphological traits showed similar dark green colour, leaf shape, deep flower colour intensity, red buds, brown keel tip and prostrate habit except for nearly $25 \%$ of the tetraploid individuals of population 4 , which exhibited a lighter green colour, light flower colour and/or erect habit similar to that observed in plants from many L. corniculatus cultivars including San Gabriel.

For quantitative traits, tetraploids had a greater mean size than diploids (Table 2). The MANOVA showed significant variation in plant phenotype between cytotypes (Pillai's trace $=0.80, P<0.0001$ ). Standardized canonical coefficients (Table 2) showed that the cytotype effect was attributable to five main characters; stem length (1), internode length (2), keel width (10), standard length (7) and flower number per umbel (11). The MANOvas performed on each cytotype separately showed significant differences between populations in both diploids (Pillai's trace $=0.66, P<0.0001$ ) and tetraploids (Pillai's trace $=0.39, P<0.001$ ). In the diploids, stem length (1), leaf length (3), leaf width (4), keel width (10) and ovary length (12) were the most important traits contributing to the variation between the two populations (Table 2). In the tetraploids, the most discriminating traits were leaf length (3), leaf width (4), standard length (7), keel length (9) and keel width (10) (Table 2). Similar results were obtained from the plants cultivated in uniform conditions and those measured in situ. However, ANOvA of each character showed significant differences between the diploid populations for all characters, but no differences between the tetraploid populations.

The morphological index in the populations cultivated under uniform conditions illustrates that morphological divergence occurs between diploid and tetraploid plants and between populations within each ploidy level (Fig. 2). Based on morphological data, population 3 was closer to the diploid populations than population 4 in which some of the individuals had very large leaves and/or long internodes leading to an increased standard deviation. Increases in both leaf length and standard length mean values in population 4 illustrate the morphological similarity of individuals of this population and the cultivar Leo, which exhibited similar values for these organs (i.e. $12.00 \pm 0.33 \mathrm{~mm}$ for leaf length and $12.70 \pm 0.77 \mathrm{~mm}$ for standard length).

\section{Chromosome pairing at meiosis and inheritance of isozymes}

Bivalents were observed exclusively in all the meioses examined from the 22 tetraploid individuals analysed. Allele segregations at the $A c P H 1$ and 
Table 2 Means and standard deviations for 12 morphological characters measured on 40 individual plants in the diploid (1 and 2) and the tetraploid (3 and 4) Alpine Lotus populations

\begin{tabular}{|c|c|c|c|c|c|c|c|c|c|c|c|}
\hline \multirow[b]{2}{*}{ Characters } & \multicolumn{2}{|c|}{$1(2 x)$} & \multicolumn{2}{|c|}{$2(2 x)$} & \multicolumn{2}{|c|}{$3(4 x)$} & \multicolumn{2}{|c|}{$4(4 x)$} & \multicolumn{3}{|c|}{$\begin{array}{l}\text { Standardized canonical } \\
\text { coefficient }\end{array}$} \\
\hline & Mean & $\mathrm{SD}$ & Mean & $\mathrm{SD}$ & Mean & $\mathrm{SD}$ & Mean & $\mathrm{SD}$ & Cytotypes & $2 \mathrm{x}$ pop. & 4x pop. \\
\hline 1 Stem length $(\mathrm{cm})$ & 5.10 & 0.23 & 8.48 & 0.37 & 13.90 & 0.75 & 14.16 & 0.77 & 0.9584 & 0.5032 & -0.3261 \\
\hline 2 Internode length $(\mathrm{cm})$ & 1.74 & 0.09 & 2.15 & 0.12 & 3.88 & 0.14 & 4.15 & 0.33 & 0.7035 & 0.1492 & 0.2116 \\
\hline 3 Leaf length $(\mathrm{mm})$ & 6.51 & 0.18 & 8.40 & 0.23 & 10.30 & 0.36 & 10.63 & 0.47 & -0.3387 & 0.7383 & -1.5168 \\
\hline 4 Leaf width (mm) & 3.25 & 0.08 & 4.21 & 0.10 & 4.82 & 0.18 & 5.44 & 0.27 & 0.1052 & -0.3928 & 1.3193 \\
\hline 5 Calix length $(\mathrm{mm})$ & 5.80 & 0.08 & 6.34 & 0.10 & 6.71 & 0.15 & 7.22 & 0.20 & -0.0157 & -0.0771 & -0.4546 \\
\hline 6 Calix teeth length $(\mathrm{mm})$ & 2.75 & 0.06 & 3.11 & 0.07 & 3.23 & 0.10 & 3.60 & 0.18 & -0.0552 & 0.1096 & -0.0539 \\
\hline 7 Standard length $(\mathrm{mm})$ & 10.65 & 0.14 & 11.17 & 0.10 & 12.40 & 0.22 & 12.57 & 0.22 & 0.4276 & 0.2163 & 0.8280 \\
\hline 8 Standard width (mm) & 8.49 & 0.15 & 8.47 & 0.13 & 8.90 & 0.16 & 9.81 & 0.20 & 0.1615 & -0.2698 & 0.3512 \\
\hline 9 Keel length (mm) & 9.75 & 0.10 & 10.44 & 0.11 & 10.82 & 0.16 & 11.26 & 0.15 & -0.1296 & 0.3618 & -1.4716 \\
\hline 10 Keel width (mm) & 3.76 & 0.05 & 3.58 & 0.06 & 3.79 & 0.08 & 3.90 & 0.07 & -0.4263 & -0.7461 & 0.5678 \\
\hline 11 Flowers/umbel & 2.28 & 0.07 & 2.20 & 0.09 & 3.89 & 0.12 & 4.00 & 0.16 & 0.9601 & 0.0427 & 0.1278 \\
\hline 12 Ovary length $(\mathrm{mm})$ & 5.61 & 0.09 & 6.47 & 0.09 & 6.73 & 0.13 & 7.03 & 0.16 & -0.0215 & 0.5574 & 0.0062 \\
\hline
\end{tabular}

Standardized canonical coefficients obtained for each character in three MANOvAs comparing the two cytotypes and the two populations in each cytotype are also indicated. Bold numbers indicate the most important traits contributing to the variation between cytotypes and populations.

EST1 loci fit the expected tetrasomic ratio and not the two-loci disomic model of inheritance (Table 3). For $L A P 1$, lack of appropriate allelic variation prevented discrimination between disomic and tetrasomic inheritance, although frequencies observed in the two progenies (Table 3) clearly support the occurrence of a single locus with two co-dominant alleles.

\section{Allozyme variation in diploid and tetraploid populations}

The two cytotypes shared 19 of the 24 alleles observed (Table 4). Two low-frequency alleles, namely 6-PGDH2-85 and IDH1-2-68, were specific to the diploids, and three other low-frequency alleles, 6-PGDH1-120, AcPH1-120 and 6-PGDH275 , were specific to the tetraploids. Moreover, alleles AcPH1-120, LAP1-102 and 6-PGDH2-75 were present in the natural Alpine populations, either exclusively in the tetraploid level or in both ploidies, but were not observed in the cultivar San Gabriel. For slow PGIs, three diploid plants showed phenograms corresponding to digenic simplex (e.g. $a_{1} a_{1} a_{1} a_{2}$ vs. $a_{1} \mathrm{a}_{1} \mathrm{a}_{2} \mathrm{a}_{2}$ for a digenic duplex) genotypes, suggesting the occurrence of gene duplication, which was also observed at the tetraploid level.

Apart from observed heterozygosity, which was higher in tetraploid populations $(P<0.05)$, MannWhitney $U$-tests and percentage comparisons showed no significant differences among cytotypes and origins for the different genetic parameters (Table 5).

Total genetic diversity $\left(H_{\mathrm{T}}\right)$ varied from 0.287 in the diploid populations to 0.308 in all the populations and the three tetraploid natural Alpine populations. A very high proportion of this genetic diversity occurred within populations $\left(H_{\mathrm{s}}>0.27\right)$. The $G_{\mathrm{ST}}$ value was higher in the diploids $(3.02 \%)$ than in the three tetraploid Alpine natural populations (1.34\%). In the tetraploids, the $G_{\mathrm{ST}}$ value increased when the cultivar was added to the natural populations $(1.95 \%)$. Over all populations, within and between population diversity within each ploidy level and diversity between the ploidy level accounted for $95.1 \%, 1.2 \%$ and $3.7 \%$ of total diversity respectively.

Nei's identity between populations ranged from $95.8 \%$ between populations 3 and 2 to $99.5 \%$ between populations 3 and 4 , with a mean value of $97 \%$. The two diploid populations clustered together at the $55 \%$ level and were clearly separated from the tetraploid ones, which clustered together at a lower level $(23 \%)$ (Fig. 3). At the $8 \%$ clustering level, the three natural tetraploid Alpine populations were grouped together and were separated from the cultivar.

Compared with expected values assuming panmixia in all the populations and postulating tetrasomic inheritance in the tetraploids, genotype distribution showed significant differences from 
Hardy-Weinberg expectations at locus LAP1 in populations $1 \quad(P<0.01), 2(P<0.02), 3 \quad(P<0.05)$ and $4(P<0.01)$, and at locus $A c P H 1$ in populations 3,4 and $5(P<0.001$ in all cases $)$. Significant differences at the $L A P 1$ locus were caused by a deficit of heterozygotes in the diploid and by a deficit of duplex (e.g. $\left.a_{1} a_{1} a_{2} a_{2}\right)$ heterozygotes in the tetraploid. At the $A c P H 1$ locus, a deficit of genotypes with three and four alleles was observed.

\section{Discussion}

Identity and putative origin of tetraploid Lotus in the French Alps

In the present study, with the exception of a few Lotus plants from population 4, substantial morphological and allozyme homogeneity was observed
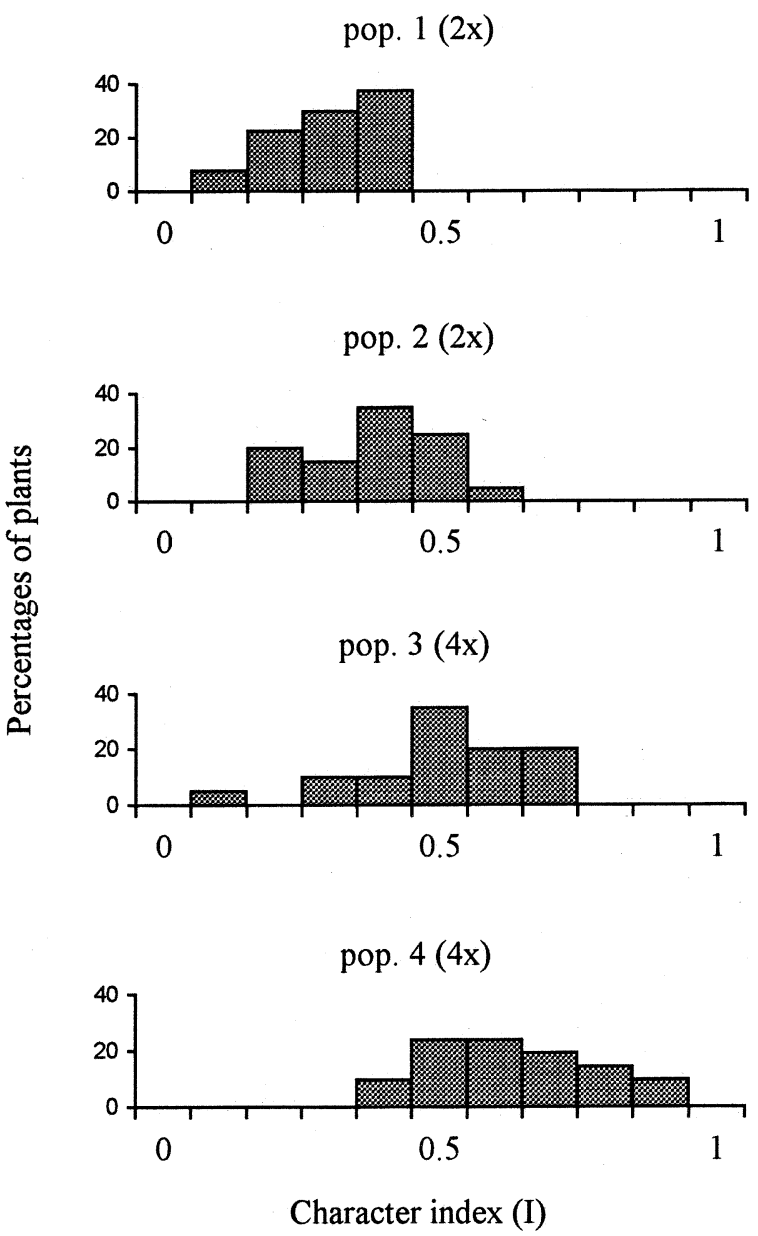

Fig. 2 Frequency distribution of character indices based on three morphological traits (leaf length, leaf width and keel length) in the diploid (1 and 2 ) and the tetraploid (3 and 4) Alpine Lotus populations.

(C) The Genetical Society of Great Britain, Heredity, 80, 683-693. within the natural tetraploids, suggesting that they probably constitute a single taxon. Although no tetravalents could be identified in meiosis of the tetraploid individuals, the occurrence of tetrasomic inheritance at two enzyme loci provided clear evidence for an autopolyploid origin of the tetraploid cytotype growing at middle and high elevations in the Alpine region. Tetrasomic inheritance is considered as a critical genetic criterion for an autotetraploid (Stebbins, 1950) and has been demonstrated for several loci in tetraploids of Tolmiea menziesii (Soltis \& Soltis, 1988) and of L. corniculatus (Dawson, 1941; Jones \& Turkington, 1986), which, like L. alpinus, do not show tetravalents at meiosis. Although the occurrence of $2 n$ gametes was not studied in diploid L. alpinus, sexual polyploidization is a likely origin of the tetraploid. Indeed, a high frequency of unreduced gametes was observed in L. tenuis (Negri \& Veronesi, 1989), which belongs to the L. corniculatus group.

Morphological variation in both Lotus cytotypes also suggests that the tetraploids may be of autopolyploid origin and that L. alpinus may be their diploid ancestor. In the Alpine populations studied in the present work, plants of both ploidies showed similar nonsize morphological characters (e.g. leaf colour and shape, flower colour intensity and plant habit). These traits were distinct from those described in other closely related Lotus species, including $L$. tenuis and $L$. corniculatus, which grow in the same region (Grant \& Small, 1996). In the present study, significant morphological differences were also observed between the diploid and the tetraploid plants whatever their geographical origin, and individuals of both ploidy levels could easily be distinguished both in situ and in the greenhouse. However, discrimination between diploids and tetraploids was based exclusively on the size of certain vegetative traits and flower number per umbel, which were greater in polyploids.

In the present study, significant morphological variation was also observed for quantitative characters between populations of each ploidy level. In diploids, smaller values were obtained both in situ and in the greenhouse for plants from La Sassière compared with those from Mount Jovet. This may be related to the distinct microclimatic conditions in the two sites, particularly the shorter growing season in the former. Morphological differences between the two tetraploid populations may also reflect environmental differences between the two sites, but additional variation was likely because of very high morphological heterogeneity occurring among groups of plants within population 4 . The origin of 
Table 3 Inheritance of $A c P H 1, E S T 1$ and $L A P 1$ in tetraploid Lotus alpinus

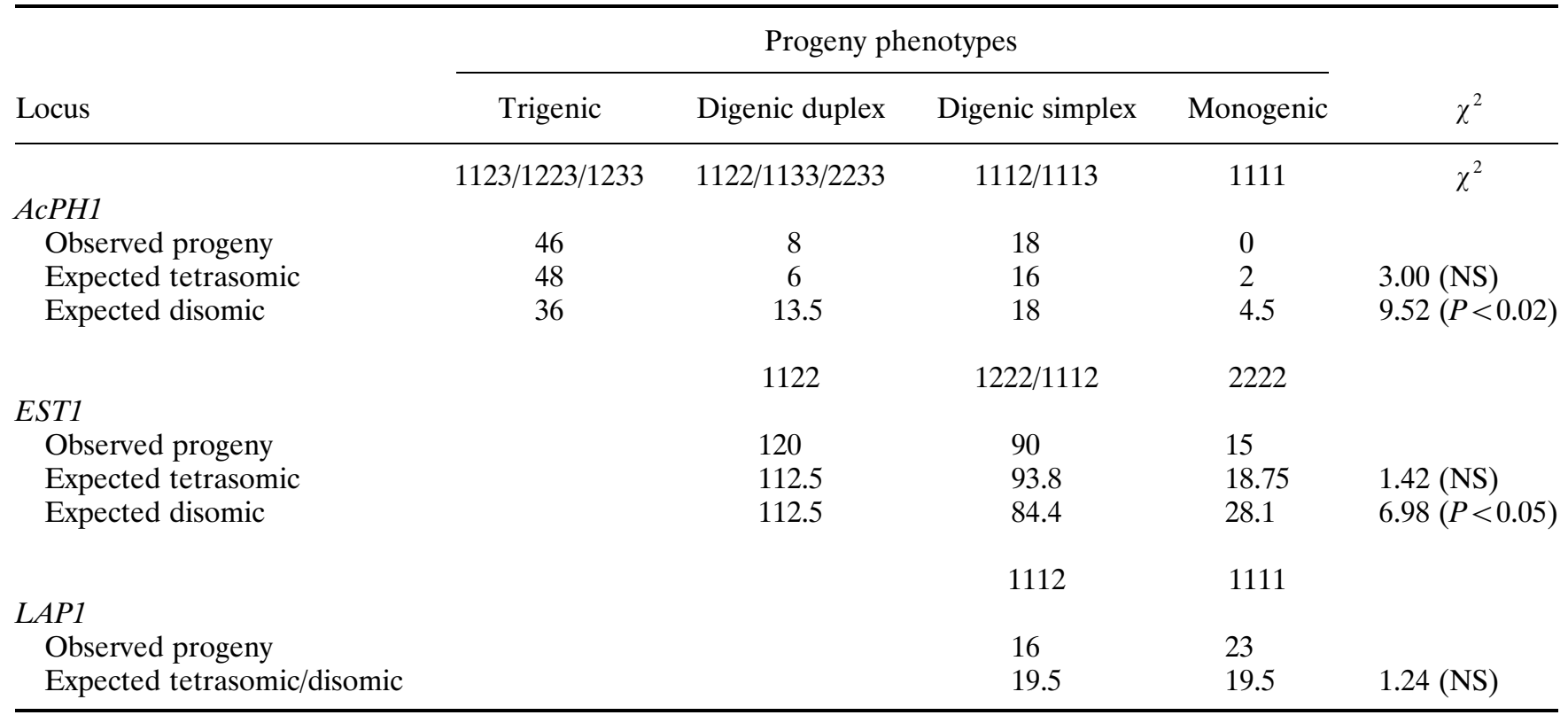

Putative genotypes crossed were $1122 \times 1133$ for $A c P H 1,1122 \times 1222$ for $E S T 1$ and $1111 \times 1112$ for LAP1. Goodness-of-fit $\chi^{2}$ tests for tetrasomic and/or two-locus disomic models of inheritance are provided.

such variation will be discussed at the end of the paper.

Allozyme variation in the diploid and tetraploid Lotus is also consistent with the hypothesis of an autopolyploid origin of the tetraploids from the diploid L. alpinus. Both cytotypes possess a nearly identical suite of allozymes at all loci with the same alleles being predominant in most cases. However, most (but not all) of these alleles were also present in the L. corniculatus cultivar analysed in this study and have been recorded in cultivars and natural populations of $L$. corniculatus studied by Realson \& Grant (1988). Because of allozyme similarity, these authors considered the diploid L. alpinus as a putative ancestor of L. corniculatus. Evidence obtained from a study of chloroplast DNA variation in several species of the $L$. corniculatus group suggests that $L$. alpinus is not the maternal ancestor of L. corniculatus (Gauthier et al., 1997), but the possibility that this diploid may have contributed as a paternal ancestor to the genome of $L$. corniculatus cannot be ruled out completely. Our results were generally consistent with those obtained with the same enzyme markers by Realson \& Grant (1988, 1989). Unlike these authors, however, we observed a few diploid plants with a digenic simplex composition at loci coding for cytosolic PGI enzymes, suggesting the occurrence of gene duplication at the diploid level. As observed previously for duplicated PGI loci in diploids of other plant species, for example Dactylis glomerata (Lumaret, 1986), there was a large excess of digenic duplex individuals in diploid $L$. alpinus. This excess may be caused by the tandem duplication itself, which favours the occurrence of two copies of the same allele on the same chromosome with a low probability of recombination, or by a selective advantage for individuals possessing balanced relative amounts of the same enzymes.

In the Lotus populations analysed in the present work, as would be expected given tetrasomic inheritance, tetraploids displayed statistically higher numbers of observed heterozygotes $\left(H_{\mathrm{o}}\right)$ than diploids. However, several other genetic parameters, including genetic diversity (Table 5), were very similar for both ploidy levels or only slightly higher in tetraploids. Allozyme polymorphism and diversity are higher in autopolyploids than in related diploids in many (but not all) taxa studied previously (see Soltis \& Soltis, 1993 for a review). According to Stebbins (1985), the evolutionary success of polyploids should be related directly to their higher heterozygosity, because the adaptive effect of polyploids would result from the increase in distinct functional alleles at one locus. In Alpine Lotus, as in Heuchera micrantha (Ness et al., 1989), increased heterozygosity in the tetraploid may not be the result of numerous new alleles not found in the diploid but is probably directly attributable to the tetrasomic genetic structure, which is characterized by high inertia, so that many loci are maintained in 
the heterozygous state for a long period. Indeed, selection cannot remove deleterious recessive alleles because homozygosity is not 'common' for rare alleles. Differences between disomic and tetrasomic genetic structures are important determinants of the separation between diploid and tetraploid Lotus populations in UPGMA phenograms, although the genetic identity of the two ploidies was high. Similar results have been observed in sympatric cytotypes of several other autopolyploid complexes, such as in Dactylis glomerata (Lumaret \& Barrientos, 1990) and in Arrhenatherum elatius (Petit et al., 1997).

\section{Gene flow between diploids and tetraploids}

In the present study, the occurrence of several low-frequency allozymes specific to either diploids or tetraploids had little impact on genetic differentiation between ploidy levels, but clearly indicates that gene flow is limited between them. In sympatric or parapatric areas, reduced gene flow between entities of the same autopolyploid complex has been shown to be necessary to maintain sufficient genetic differentiation between them and to ensure their co-existence (Thompson \& Lumaret, 1992). Reduced gene flow between cytotypes may result from spatial isolation and habitat differentiation and/or phenotypic differences in flowering time. In Alpine Lotus, the two cytotypes have distinct elevation ranges, which correspond to different climatic conditions. Furthermore, tetraploids flower earlier than the diploids. Where intermediate areas are colonized by Lotus plants, as on Mount Jovet, a very narrow distribution of mixed cytotypes may occur

Table 4 Allelic frequencies at 12 polymorphic loci in diploid and tetraploid Alpine Lotus populations and the L. corniculatus cultivar San Gabriel

\begin{tabular}{|c|c|c|c|c|c|c|c|c|}
\hline \multirow[b]{3}{*}{ Locus } & \multirow[b]{3}{*}{ Allele } & \multirow[b]{3}{*}{$\mathrm{Cp}$} & \multicolumn{6}{|c|}{ Populations } \\
\hline & & & \multicolumn{5}{|c|}{ Alpine } & \multirow{2}{*}{$\frac{\text { Cultivar }}{(4 \mathrm{x})}$} \\
\hline & & & $1(2 x)$ & $2(2 x)$ & $3(4 x)$ & $4(4 x)$ & $5(4 x)$ & \\
\hline \multirow[t]{5}{*}{$A c P H 1$} & 120 & & - & - & 0.06 & 0.10 & 0.07 & - \\
\hline & 115 & & 0.09 & 0.45 & 0.12 & 0.12 & 0.19 & 0.09 \\
\hline & 110 & & 0.43 & 0.16 & 0.20 & 0.32 & 0.16 & 0.26 \\
\hline & 100 & & 0.34 & 0.31 & 0.59 & 0.42 & 0.53 & 0.53 \\
\hline & 86 & & 0.14 & 0.08 & 0.03 & 0.04 & 0.05 & 0.12 \\
\hline \multirow[t]{3}{*}{ IDH1-2 } & 100 & $(100)$ & 0.73 & 0.63 & 0.47 & 0.38 & 0.46 & 0.47 \\
\hline & 85 & $(85)$ & 0.27 & 0.30 & 0.53 & 0.62 & 0.54 & 0.53 \\
\hline & 68 & & - & 0.07 & - & - & - & - \\
\hline \multirow[t]{3}{*}{$L A P 1$} & 102 & & 0.07 & 0.02 & - & - & 0.02 & - \\
\hline & 100 & & 0.62 & 0.72 & 0.62 & 0.63 & 0.69 & 0.87 \\
\hline & 96 & & 0.31 & 0.26 & 0.38 & 0.37 & 0.29 & 0.13 \\
\hline \multirow[t]{2}{*}{$M D H 3$} & 136 & (85) & 0.03 & - & 0.01 & - & 0.04 & 0.06 \\
\hline & 100 & (66) & 0.97 & 1.00 & 0.99 & 1.00 & 0.96 & 0.94 \\
\hline \multirow{2}{*}{$\begin{array}{l}\text { 6-PGDH1-2 } \\
\quad(6-P G D H 1)\end{array}$} & 120 & $(120)$ & - & - & - & - & 0.03 & 0.01 \\
\hline & 100 & (100) & 1.00 & 1.00 & 1.00 & 1.00 & 0.97 & 0.99 \\
\hline \multirow{3}{*}{$\begin{array}{l}\text { 6-PGDH3-4 } \\
\quad(6-P G D H 2)\end{array}$} & 100 & $(80)$ & 0.98 & 0.91 & 0.95 & 0.98 & 0.99 & 1.00 \\
\hline & 85 & $(65)$ & 0.02 & 0.09 & - & - & - & - \\
\hline & 75 & & - & - & 0.05 & 0.02 & 0.01 & - \\
\hline \multirow{4}{*}{$\begin{array}{l}P G 12-3 \\
\quad(P G I 2)\end{array}$} & 110 & $(80)$ & - & 0.02 & 0.01 & 0.02 & 0.02 & 0.06 \\
\hline & 100 & (72) & 0.70 & 0.79 & 0.42 & 0.50 & 0.60 & 0.45 \\
\hline & 87 & (62) & 0.06 & 0.04 & 0.14 & 0.12 & 0.15 & 0.17 \\
\hline & 70 & (52) & 0.24 & 0.15 & 0.43 & 0.36 & 0.23 & 0.32 \\
\hline \multirow[t]{2}{*}{ TO1 } & 108 & & 0.07 & 0.05 & 0.07 & 0.05 & 0.12 & 0.10 \\
\hline & 100 & & 0.93 & 0.95 & 0.93 & 0.95 & 0.88 & 0.90 \\
\hline
\end{tabular}

Correspondence with allelic denomination of Realson \& Grant (1988) is indicated in the column Cp and in brackets. PGI2-3, IDH1-2, 6-PGDH1-2 and 6-PGDH3-4 are duplicated loci. 
Table 5 Percentage of polymorphic loci $(P)$, total number of alleles $\left(A_{\mathrm{t}}\right)$, mean number of alleles per polymorphic locus $(A)$, observed heterozygosity $\left(H_{\mathrm{o}}\right)$ and gene diversity $\left(H_{\mathrm{s}}\right)$ in the five Alpine Lotus populations (1-5) and in the L. corniculatus cultivar (6)

\begin{tabular}{lccccc}
\hline Population & $P(\%)$ & $A_{\mathrm{t}}$ & $A$ & $H_{\mathrm{o}}(\%)$ & $H_{\mathrm{s}}(\%)$ \\
\hline $1(2 \mathrm{x})$ & 84 & 19 & 2.5 & 23.28 & 28.2 \\
$2(2 \mathrm{x})$ & 75 & 20 & 3.0 & 20.31 & 27.5 \\
$3(4 \mathrm{x})$ & 84 & 20 & 2.7 & 45.31 & 30.1 \\
$4(4 \mathrm{x})$ & 75 & 19 & 2.8 & 40.62 & 29.6 \\
$5(4 \mathrm{x})$ & 100 & 22 & 2.7 & 57.25 & 31.7 \\
$6(4 \mathrm{x})$ & 84 & 19 & 2.6 & 46.32 & 29.2 \\
$2 x$ mean & 80 & 19.5 & 2.8 & 21.85 & 27.9 \\
$4 x$ mean & 86 & 20.0 & 2.7 & 47.38 & 30.1 \\
\hline
\end{tabular}

with a reduced number of plants of both cytotypes occurring in small distinct groups. However, phenological displacement between the cytotypes occurs in such zones. Any between-cytotype pollination may also be countered strongly by an efficient triploid block, as suggested by the absence of triploid plants both in situ and in experimental crosses between diploid and tetraploid plants (Urbanska-Worytkiewicz et al., 1979). In Alpine Lotus, such flowering period discrepancy between cytotypes is very similar to that described in the Pyrenees for diploids and autotetraploids of Plantago media (Van Dijk et al., 1992) and Arrhenatherum eliatus (Petit et al., 1997) and may fit the evolutionary model proposed by Van Dijk \& Bijlsma (1994).

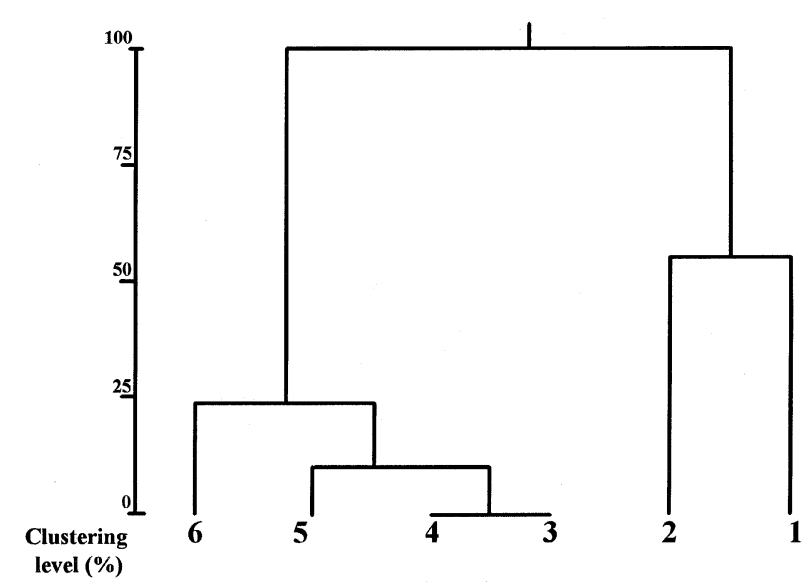

Fig. 3 UPGMA phenogram based on Nei's distance over the 12 studied enzyme loci ( $A c P H 1, I D H 1-2, L A P 1, M D H 3$, 6-PGDH1-2, 6-PGDH3-4, PGI2-3 and TO1), showing the genetic relationship between diploid (1 and 2) and tetraploid (3, 4 and 5) Alpine Lotus populations and the L. corniculatus cultivar San Gabriel (6).
Genetic introgression between tetraploid L. alpinus and tetraploid L. corniculatus

The discovery that nearly $25 \%$ of tetraploid plants derived from population 4 (Mount Jovet) exhibited various combinations of particular morphological characters, such as an erect habit, light yellow buds, large leaves and large standards, which are characteristics of $L$. corniculatus cultivars, suggested the possibility of initial hybridization and subsequent genetic introgression between the Alpine tetraploid cytotype (L. alpinus according to the results presented above) and $L$. corniculatus cultivars introduced at lower elevations. Unfortunately, such putative introgression could not be detected using allozymes, as the two tetraploid taxa displayed very similar allele pools. As L. alpinus and L. corniculatus possess very distinct chloroplast DNA (cpDNA) variants (Gauthier et al., 1997), this marker is used in a subsequent paper to confirm relationships between diploid and tetraploid Lotus in the Alps.

\section{Acknow ledgements}

This research was supported by a grant from the French ministry of the Environment 'comite EGPNSRETIE, contract no. 93179' and by $\mathrm{PhD}$ funding (P. Gauthier) from the CEMAGREF. We thank F. Bretagnolle for collecting plant material, F. Di Guisto, F. Gailleton, P. Tardif and D. Claret for technical support, J. Ronfort and C. Petit for statistical support and J. Thompson for making useful suggestions on improving the manuscript.

\section{References}

BLAise, S., CARTIER, D. AND REYNAUd, J. 1991. Evolution and differentiation of Lotus corniculatus/Lotus alpinus populations from French south-western Alps. I. Morphologic and cyanogenic variations. Evol. Trends Plants, 5, 137-148.

BRETAGNOLLE, F. AND THOMPSON, J. D. 1995. Gametes with somatic chromosome number: their mechanisms of formation and role in the evolution of autopolyploid plants. New Phytol., 129, 1-22.

BROCHMANN, C. 1987. Evaluation of some methods for hybrid analysis, exemplified by hybridization in Argyranthemum (Asteraceae). Nord. J. Bot., 7, 609-630.

CAMPOS, L. P., REALSON, J. V. AND GRANT, W. F. 1994. Genome relationships among Lotus species based on random amplified polymorphic DNA (RAPD). Theor. Appl. Genet., 88, 417-422.

DAWSON, C. D. R. 1941. Tetrasomic inheritance in Lotus corniculatus L. J. Genet., 42, 49-73.

FAVARGER, C. 1969. Note de caryologie alpine V. Bull. Soc. Neuchâtel. Sci. Nat., 76, 137-139.

(c) The Genetical Society of Great Britain, Heredity, 80, 683-693. 
GAPILlout, A. 1975. Carte écologique du bassin de Bourg Saint-Maurice. Doc. Cart. Ecol., XV, 41-58.

GAUTHIER, P., LUMARET, R. AND BÉDÉCARRATS, A. 1997. Chloroplast-DNA variation in the genus Lotus (Fabaceae) and further evidence regarding the maternal parentage of Lotus corniculatus L. Theor. Appl. Genet., 95, 629-636.

GENSAC, P. 1978. Observations thermométriques de 1973 à 1976 dans le Parc National de la Vanoise. Conséquences biologiques. Trav. Sci. Parc Nat. Vanoise, XI, $112-135$.

GRANT, w. J. AND SMALl, E. 1996. The origin of the Lotus corniculatus (Fabaceae) complex: a synthesis of diverse evidence. Can. J. Bot., 74, 975-989.

JAY, M., REYNAUD, J., BLAISE, S. AND CARTIER, D. 1991. Evolution and differentiation of Lotus corniculatus/ Lotus alpinus populations from French south-western Alps. III. Conclusions. Evol. Trends Plants, 5, 157-160.

JONES, D. A. AND TURKINGTON, R. 1986. Biological flora of the British Isles. Lotus corniculatus L. J. Ecol., 74, 1185-1212.

LEBRETON, J. D., ROUX, M., BANCO, G. AND BACOU, A. M. 1987. The вIOмЕсо package. CNRS, Montpellier, France.

LUMARET, R. 1986. Doubled duplication of the structural gene for cytosolic phosphoglucose isomerases in the Dactylis glomerata L. polyploid complex. Mol. Biol. Evol., 3, 499-521.

Lumaret, R. 1988. Cytology, genetics, and evolution in the genus Dactylis. Crit. Rev. Plant Sci., 7, 55-91.

LUMARET, R. AND BARRIENTOS, E. 1990. Phylogenetic relationships and gene flow between sympatric diploid and tetraploid plants of Dactylis glomerata (Gramineae). Pl. Syst. Evol., 169, 81-96.

LumARET, R. AND HANOTTE, C. 1987. Mise en évidence d'un écotype alpin de Dactyle (Dactylis glomerata L.) de pelouses dolomitiques subalpines dans les Grisons (Suisse): origines et échanges géniques avec les dactyles des prairies adjacentes. Acta Oecol. Plant, 8, 3-20.

NEGRI, V. AND VERONESI, F. 1989. Evidence for the existence of $2 n$ gametes in Lotus tenuis Wald. and Kit. $(2 n=2 \mathrm{x}=12)$ : their relevance in evolution and breeding of Lotus corniculatus L. $(2 n=4 \mathrm{x}=24)$. Theor. Appl. Genet., 78, 400-404.

NEI, M. 1978. Estimation of average heterozygosity and genetic distance from a small number of individuals. Genetics, 89, 583-590.

NEI, M. 1987. Molecular Evolutionary Genetics. Columbia University Press, New York.

NESS, B. D., SOlTIS, D. E. AND soltis, P. 1989. Autopolyploidy in Heuchera micrantha (Saxifragaceae). Am. J. Bot., 76, 614-626.

O'DONOUGHuE, L. S., REALSON, J. V. AND GRANT, W. F. 1990. A morphological study of interspecific hybrids in the genus Lotus (Fabaceae). Can. J. Bot., 68, 803-812.

PETIT, C., LESBRos, P., XUEJUN, G. AND THOMPSON, J. 1997. Variation in flowering phenology and selfing rate across a contact zone between diploid and tetraploid Arrhenatherum elatius (Poaceae). Heredity, 79, 31-40.

REALSON, J. AND GRANT, w. F. 1988. Evaluation of hypotheses concerning the origin of Lotus corniculatus (Fabaceae) using isozymes data. Theor. Appl. Genet., 76, 267-276.

REALSON, J. AND GRANT, w. F. 1989. An isozyme study in the genus Lotus (Fabaceae). Experimental protocols and genetic basis of electrophoretic phenotype. Theor. Appl. Genet., 77, 595-607.

SAS INSTITUTE INC. 1990. SAS/STAT User's Guide, version 6. SAS Institute Inc., Cary, NC.

SMALl, E., GRANT, W. F. AND CROMPTON, C. W. 1984. A taxonomic study of the Lotus corniculatus complex in Turkey. Can. J. Bot., 62, 1044-1053.

SOLTIS, D. E. AND SOLTIS, P. 1988. Electrophoretic evidence for tetrasomic segregation in Tolmiea menziesii (Saxifragaceae). Heredity, 60, 375-382.

soltis, D. E. AND soltis, P. S. 1989. Isozymes in Plant Biology. Chapman and Hall, London.

SOLTIS, D. E. AND SOLTIS, P. S. 1993. Molecular data and the dynamic nature of polyploidy. Crit. Rev. Plant Sci., 12, 243-273.

Stebins, G. L. 1950. Variation and Evolution in Plants. Columbia University Press, New York.

StebBins, G. L. 1985. Polyploidy, hybridisation and the invasion of new habitats. Ann. Mo. Bot. Gard., 72, 824-832.

THOMPSON, J. D. AND LUMARET, R. 1992. The evolutionary dynamics of polyploid plants: origins, establishment and persistence. Trends Ecol. Evol., 7, 302-306.

URBANSKA-WORYTKIEWICZ, K. AND WILDI, O. 1975. Variation within Lotus corniculatus L. s.l. from Switzerland. I. Preliminary report on chromosome numbers and cyanogenesis. Ber. Geobot. Inst. ETH Stift. Ruebel Zuer, 43, 54-82.

URBANSKA-WORYTKIEWICZ, K., SCHWANK, O. AND FOSSATI, A. 1979. Variation within Lotus corniculatus L. s.l. from Switzerland. II. Reproductive behaviour of Lotus alpinus (DC) Schleicher. Ber. Geobot. Inst. ETH Stift. Ruebel Zuer, 46, 62-48.

VAN DIJK, P. AND BIJLSMA, R. 1994. Simulations of flowering time displacement between two cytotypes that form inviable hybrids. Heredity, 72, 522-535.

VAN DIJK, P., HARTOG, M. AND VAN DELDEN, w. 1992. Single cytotype areas in autopolyploid Plantago media L. Biol. J. Linn. Soc., 46, 315-331.

WEEDEN, N. F. AND WENDEL, J. F. 1989. Genetics of plant isozymes. In: Soltis, D. E. and Soltis, P. S (eds). Isozymes in Plant Biology, pp. 46-72. Chapman and Hall, London. 